Opinion

\title{
Opinion on anticancer environment
}

\section{Opinion}

I remember a colleague of mine in medical school who never believed in the current methods of treating cancer and claiming cure for some of the cases. He was particularly adamant on the oldest method, surgery, saying it didn't not address the root cause and that the cancer was bound to return. Hence cure for him was misleading and called for alternative ways of fighting cancer.

These kind of arguments were not the first in the field of oncology and as we learn more and more about cancer over the years, treatments has so evolved. In the early days surgery was the only treatment for cancerous tumors but inclusion of the chemotherapy and radiation before and after surgery was meant to address the fact that surgery on its own was not optimal. In the days of the famous Greek physician Hippocrates, Surgery was not practiced for the less visible and visceral cancers.

Though effective, it was discovered after surgery they would still be cancer remnants because there were small cancer cells called circulating tumor cells (CTCs) in the blood stream. A surgeon's knife cannot eliminate these.

Though chemotherapy and radiation has been able to add many years to cancer after going surgery, enabling people to live longer after the cancer diagnosis, many a times the cancers return and when it does its usually more aggressive.

What should makes it return? Is it possible after all the gruesome experience of surgery, chemotherapy and even radiotherapy we are still unable to say with confidence that all the cancer has been wiped out? And if it's a new cancer, why return to a patient who has already received treatment, and a times very aggressive treatment.

There has been an increase in the cancer cases worldwide since in the 1940s especially in the industrialized world. A particular striking observation is the rise on cancer in the young. A recent study by the American cancer society researchers found out for the adults between 20 and 39, colon cancer went up by $1 \%$ to $2 \%$ per year for the 2013 . For adults of ages 40 and 54 the rate was about $0.5 \%$ and $1 \%$ per year. Breast cancer is no longer the disease for the old as pointed out by a study in America that showed a rise of 3.9\% for women aged between 25 and 39 for the years 2000 and 2009.

Numerous reasons have been forwarded to explain the rise in cancer cases and one of them is that we have better diagnostic todays and hence able to detect early through many screening methods. However cancers that are not routinely screened like lymphoma, brain cancers and lung cancers and pancreas have increased. There are some who claim that the world population today lives longer and hence the risk for risk for cancer increased. However the observation that we have cancer cases rise in the young does not support that notion.

In the past when cancer was mainly for the young, the environment was different as the one we have today. It's so possible that we as
Volume 9 Issue I - 2018

\author{
Heri M Tungaraza \\ Oncologist, Muhimbili National Hospital,Wenzhou medical \\ University, Tanzania
}

Correspondence: Heri M Tungaraza MD, Mmed-Oncology, Muhimbili National Hospital,Wenzhou medical University, Tanzania, Email tungarazah@gmail.com

Received: December 15, 2017 | Published: January 31, 2018

humans our biology has not changed but the environment have changed so much. It is this environment that fosters the growth of different cancers in different populations.

Today we have more polluted lands and waters and hence we feed on toxins after toxins weakening our bodies before the attacking monster of them all. So our diets that is majorly from of plants grown on polluted lands of animals fed on toxin enriched foods could be the very reason we have having the cancer numbers rise.

So many friends were right, modern treatment might be the real cure against any cancer and that today's oncologist must appreciate this and hence changed their mindset. The answers are not only on their chemo, surgery and radiation as taught in medical school. After all the conventional treatments patients should be well educated on the realistic changes they need to make to their lives so as to detoxify their bodies and the environment at large. Maybe in so doing, the cancer will never return for good.

\section{Conflicts of interest}

None.

\section{Acknowledgements}

None.

\section{Funding}

None. 